\title{
Making sense of bridge monitoring: Vision for the future
}

\author{
Aleksandar Pavic \\ Professor of Vibration Engineering, College of Engineering, Mathematical and Physical Sciences, \\ University of Exeter, Exeter, UK
}

James M.W. Brownjohn

Full Scale Dynamics Ltd, The Sheffield Bioincubator, Sheffield, UK

\begin{abstract}
This paper presents a vision for the future monitoring systems which will become normal requirements for management of bridges as key objects of national infrastructure in the UK and elsewhere. Rather than being pushed by authorities and legislation, we expect that bridge managers will recognize the clear business cases for investing in well-designed targeted monitoring. To support this proposition, the paper presents two case studied where state-of-the-art bridge monitoring technology was used or potentially could be used to:
\end{abstract}

- Decide when to inspect and change bridge bearings, and

- Decide when to close various traffic lanes to reduce probability of overstressing bridge structural components.

\section{INTRODUCTION}

The UK Government's 2011 National Infrastructure Plan [1] signalled the need for investments of up to $£ 250$ bn over 10 years to return UK infrastructure (transport, power, communications, water, and waste) to world class levels of performance. Only about a third of this can be provided from a public purse in the UK. The rest must come from private funding most likely overseas sovereign investment funds. The key problem is clearly how to attract such funding and how to convince private finance that the investment in the UK infrastructure is sound. Having hard data about past and future physical performance of such infrastructure is a way forward to justify investment and attract private funding. In fact, it could well be the only way forward.

Focusing on bridges as key elements of any national infrastructure, the American Society of Civil Engineers (ASCE) reports a cost of $\$ 140 \mathrm{bn}$ to repair all deficient bridges in the United States [2]. Similar to the UK, whilst taxpayers in the USA can be expected to fund a small proportion of such enormous investment, as for the general infrastructure mentioned above, the remainder must come from private sources. The primary requirements for attracting both private and public investment in an infrastructure asset are managed risk and reliability of performance in continuous operation with ever increasing service and safety demands. Maximising return on investment requires minimisation of costs necessary to achieve that performance - put simply getting more from less. These requirements highlight the process of the whole-life performance management of civil infrastructure, a process involving decisions about design, construction, operation, maintenance, repair, decommissioning and demolition. Ensuring that such decisions are informed, correct and cost effective is the most important unsolved challenge in civil infrastructure management, attracting hundreds of researchers and multi-£M global research investment. These people and this investment are all trying to solve one of the most challenging problems in civil structural engineering nowadays: how to convert testing and monitoring data from objects of infrastructure, into knowledge and decision making when managing infrastructure as public assets? The problem is particularly acute for bridges, considering their importance, and is really about how to make sense of bridge testing and monitoring data. This research has yet to deliver significant benefits in the real world due to incoherent engagement with stakeholders, misdirected emphasis in the past focusing on hardware rather than data interpretation, tendency to view infrastructure assets in isolation and the lack of a systematic approach to link experiences between different structures. This is a recognised problem in the USA and Federal Highway Administration (FHWA) are still "working the problem" [4].

Focusing on bridges, the above stated problem is obviously not new. A paradigm shift is needed across the board and with all stakeholders in the way how bridges are managed from their conception to their decommissioning. Considerable cultural changes are needed and these will follow changes in the business models used for managing bridges including the legal 
and economical framework within which public assets like bridges operate. This applies not only to the USA, but also to the UK, Europe and rest of the world. The prolonged crisis which has been shaking the foundations of the world economy for several years now may well become a badly needed catalyst for the required paradigm shift.

The continued drive for better and more enduring performance from bridges is crippled by the lack of technically sound, reliable, harmonised and economic means for monitoring asset condition. Hence, informed decision making by bridge managers is severely impaired. There is potential nowadays to transform monitoring into an enabling technology that will revolutionise the decision making process at all stages of an infrastructure's life-cycle: from design to demolition. This will yield extraordinary reduction of the currently very high direct and indirect cost of bridge performance management. The enabling technology will also foster growth of the infrastructure monitoring and decision support systems as a new technology sector which key role would be to resolve the £multi-trillion global challenge of managing deteriorating and failing infrastructure.

The aim of this invited paper is therefore to present a case and vision for this paradigm shift, making use of existing examples not only in civil engineering, but also in other engineering disciplines where such paradigm shifts happened and changed forever the ways how industries operated.

\section{FUNDAMENTAL CAUSES OF PROBLEM}

In essence, the problem lies in the nature of civil structural engineering design and disproportionately low level and certainty of information on which it is based relative to the huge importance of such structures. Because of this, in civil engineering the acceptable level of risk of structural failure or lack of its serviceability is at least an order of magnitude lower than for more technologically advanced structures employed in mechanical and aerospace engineering. There are three key reasons for this low risk approach:

1. Civil infrastructure, in particular major long-span bridges, underpin human society and supports not only traffic but the daily lives of hundreds of thousands of people and economies of linked regions.

2. Unlike aircraft, automobiles, trains and other mass produced machinery, which are extensively tested as prototypes during their design, objects of civil infrastructure including bridges are unique one-off designs with no opportunity for extensive prototype testing during design and before going into service. As such, they are designed with considerably reduced knowledge base and their structural performance is poorly understood making prediction of future behaviour difficult if not impossible.

3. The ambiguity and degree of uncertainty related to the actual operation of the structure, and potential increases in load and usage in the future, force the use of an extremely conservative design embedded in design guidelines which are used instead of prototype testing.

Notwithstanding the low-risk design methodology, critical infrastructure items such bridges deteriorate with time to such a point that, if no action is taken, they become unserviceable requiring closure and repairs, or may even collapse. To guard against this, operating authorities prescribe methods of routine, typically visual, inspection, which are slow, costly, and subjective, hence potentially quite unreliable.

The prime example of the dubious reliability of the current bridge inspection regime was generated in the UK during winter 2011/2012. A sudden and totally unexpected decision to completely close the Hammersmith flyover in London was made on 23 December 2011 after many nights of closure of the flyover for maintenance and visual inspection throughout 2011. This structure takes 90,000 vehicles per day on a strategically vital A4 route making it the prime gateway to London, not just for the West of the country, but also for one of the world's largest and busiest airports at Heathrow. This prime route remained completely closed until 13 January 2012, causing traffic chaos in West London for a period of three weeks, covering the Christmas and New Year holidays before partial reopening slightly reduced the chaos. This situation lasted for months. Apparently, an exceptional overloading event worsened the state of corroded tensioning cables of the 50-year old structure so that they started snapping at a rate fast enough for the authorities to close the flyover. This is speculation, since the structure had not been monitored over a long enough period of time. Hence, there is no information about 'normal loading' and no evidence that that the dramatic closure was actually necessary.

If anybody thought this was a chance the identification of a new crack on the already damaged Boston Manor viaduct forced a dramatic closure of the M4 between London and Heathrow airport - a key section along the Olympic Route Network. This lasted for five days in early July 2012. The new crack had been identified in a "sensitive location" following the final stages of the complex repairs to $15 \mathrm{~mm}$ long hairline cracks discovered by chance [5] in April in welds on the viaduct just west of junction 2 near Hounslow. A $7.5 \mathrm{t}$ weight restriction on the damaged stretch had been imposed immediately, diverting coaches and lorries onto busy local roads. The latest news is that Boston Manor viaduct is beyond further repairs and will be replaced.

How many similar cases and surprise total closures are lurking within the UK fleet of key bridges on the national transportation network?

\section{THE WAY FORWARD}

Interestingly, if a sudden event happened to a Roll Royce aero-engine high above the Pacific, such as a 
lightning strike causing the engine to cough, monitoring sensors within the engine would automatically record all relevant responses. This data would be transmitted immediately from the aeroplane to the Rolls Royce 24/7 operations room in Derby, UK which continuously assesses on-line the performance of thousands of working jet engines around the world. Based on the instantaneous information from the aircraft and the expected performance, a decision would be made while the plane is still in the air if the engine requires additional inspection after landing, causing delays and financial losses. In the past and without the benefit of permanent monitoring and data streaming and analysis, this would almost certainly be the case as - similar to bridges - safety is paramount. However, it is not anymore due to this service based business model of manufacturing jet engines which is based on the on-line condition monitoring technology and instantaneous decision making process which Rolls Royce mastered and commercialised around the world. The data constantly collected from engines is invaluable to airlines as the information enables Rolls Royce to predict when engines are more likely to fail, letting the airlines schedule engine changes efficiently. Embracing such technology and innovation transformed Rolls Royce from a failing company in 1971 into a currently most successful manufacturer of jet engines in the world.

Why can't the same business model be employed in the management of bridges? Over many years in the UK there has been fragmentation of construction industry and infrastructure management characterised by significant shift towards the use of subcontracting, overly complex procurement approaches and uncertainty of future work on key infrastructure due to lack of vision and leadership. This has increased transaction costs, encouraged shortermism and deterred industry from a more strategic approach to investment in skills, technology and innovation [6]. There are, however, clear signs that this approach is changing offering great opportunities to the sector, one of them being use of permanent monitoring for effective decision making in managing key objects of infrastructure, including bridges.

\section{MOTIVATION}

Wenzel [7] noted that construction sector is conservative needing strong push to motivate it to implement new technologies, such as converting monitoring data into decision making. He outlined the following motivation drivers:

1. Responsibility-driven motivation, stemming from design standards, codes and guidelines which make mandatory requirements to instrument, monitor and interpret before deciding what to do with a particular structure, such as bridge in operation. This is particularly so when covering events such as emergencies or accidents whereby monitoring data before the event can describe what is 'normal' and data after the event can be used to establish if the structure still behaves as 'normal'. Conventional assessment in such situations tend to be overly conservative, usually to compensate for the lack of reliability.

2. Economy-driven motivation, stemming from, say, the need to reduce unnecessary maintenance costs, such as expensive and not particularly reliable regular inspections, or from the need to prioritise repairs within limited budgets which make use of more reliable information about the remaining life prediction of the structure. Another emerging motivation within this category is the need for an informed transfer of ownership from public to private hands, whereby hard data from the structure provides a more reliable information of the value and longevity of the structure which is an asset for the new owner, including their finance and insurance organisations.

3. Curiosity-driven motivation whereby forwardlooking owners, operators and-in general-clients, understand limitations of the current civil engineering design practise and want to learn about the actual behaviour to help them plan future designs.

The following example will demonstrate usefulness of monitoring in decision making about their operation.

\section{ASSESSMENT OF BRIDGE BEARINGS}

The Humber Bridge was opened in 1981. Spanning $1410 \mathrm{~m}$, it held the record of the world's longest single spans suspension bridge until 1997. The Bridge spans the Humber Estuary between Hessle (North) and Barton-on-Humber (South). The Hessle side span is $280 \mathrm{~m}$ and the Barton side span is $530 \mathrm{~m}$ (Figure 9).

The aerodynamically shaped bridge box girder is discontinuous at the towers. At each end there is a pair of 'A-frames' which are approximately $3.8 \mathrm{~m}$ tall and $3.4 \mathrm{~m}$ wide (Figure 10). These bearings primarily accommodate axial movement of the span ends, but also permit rotation of the deck in the horizontal plane and in the vertical plane of bridge axis and towers as the bridge deforms under a combination of traffic, wind and temperature effects. In total there are 12 of these bearings, four on each span.

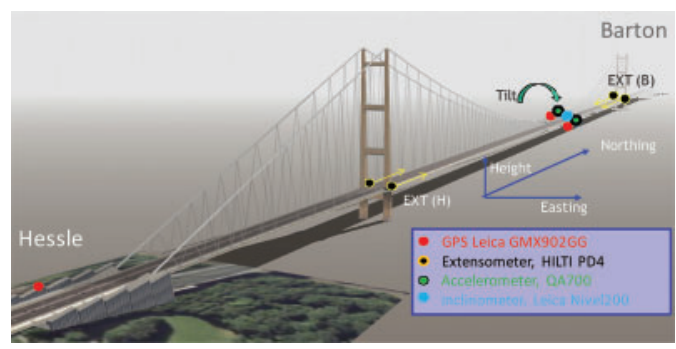

Figure 1. Humber Bridge instrumentation. 


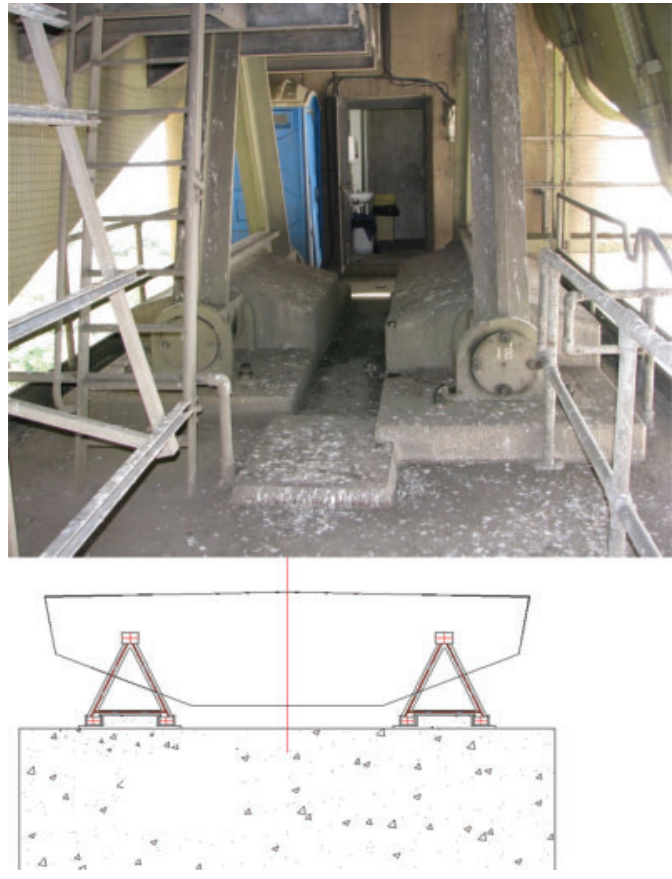

Figure 2. Top: Photo showing a pair of A-frames, one for the main and one for the side span. Bottom: The sketch shows a pair of A-frames connected to the main span box girder.

A pair of Hilti PD4 extensometers on each end of the main span was used to monitor the longitudinal deck movement at the positions of the two A-frames in Figure 10 (bottom). Hence, these two sets of data provided information to measure both longitudinal extension and horizontal plane rotation of the bridge at its end.

The end rotation is strongly dependent on wind speeds, as shown in Figure 11.

Ambient acceleration response of the deck is continuously recorded at midspan and used to estimate (in real time) the natural frequencies and damping ratios of the lowest frequency vibration modes. For the first (lateral) mode of vibration, Figure 12 shows the estimated natural frequencies as a function of the RMS of the corresponding block(s) of acceleration data. It can be seen that at about $0.2 \mathrm{~m} / \mathrm{s}^{2}$ RMS the frequency generally reduces and stabilises at about $0.054 \mathrm{~Hz}$ for higher levels of response. This indicates the likely non-linear 'stick-slip' behaviour somewhere in the structure, as confirmed by damping estimates whereby a similar 'unsticking' effect is observed roughly at the same RMS acceleration levels (Figure 13). The damping, however, is amplitude-dependent with lower damping corresponding to higher responses.

Figure 14 (top) shows diurnal variation of the four horizontal displacements measured extensiometers.

Figure 14 (bottom) cumulative quasi-static horizontal displacements of the four points on the two ends of the main span which indicate that their total travel is between $2 \mathrm{~m}$ and $3 \mathrm{~m}$ over the 10 day analysed. This means that each bearing travelled at least

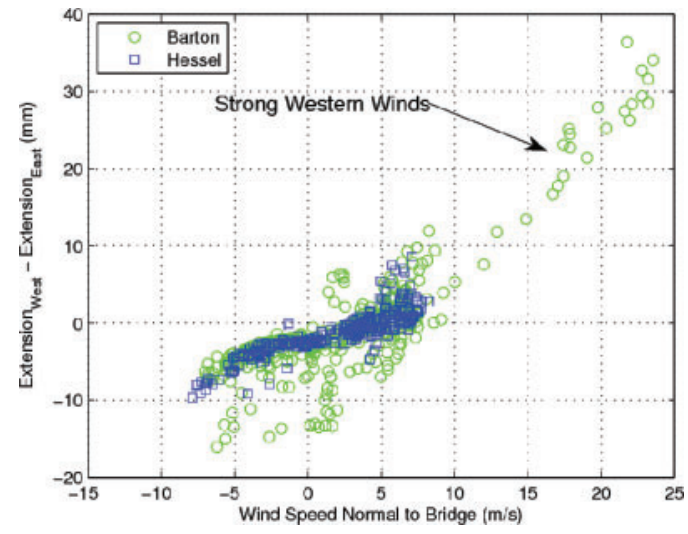

Figure 3. Hessle end rotates less than the Barton end under strong Western winds.

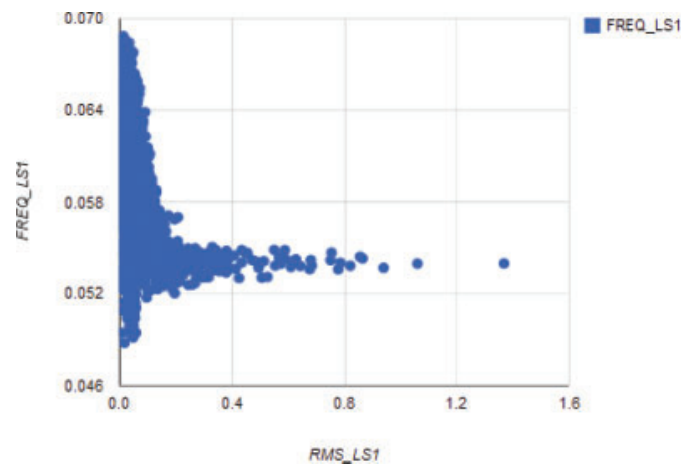

Figure 4. Amplitude-dependent natural frequency.

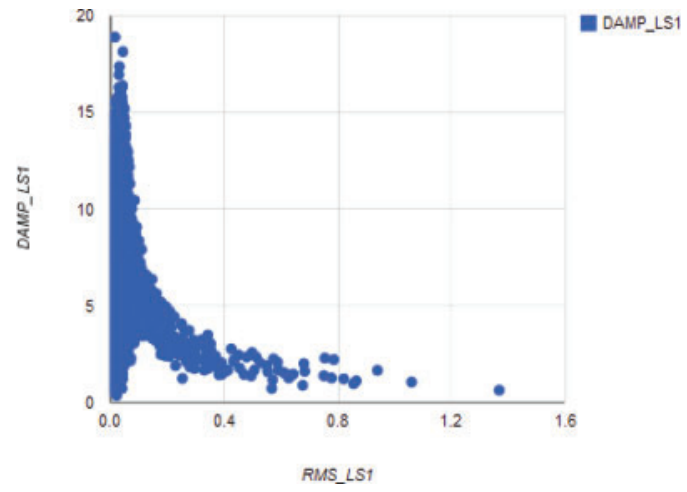

Figure 5. Amplitude-dependent damping.

$3 \mathrm{~km}$ since the opening in 1981. Not surprisingly, this has been linked with excessive wear at the A-frames and the likely stick-slip effect previously mentioned. Closer inspection indicated that one of the bearings visibly dropped and is resting on the concrete plinth underneath due to wear of the bottom of the pin-bush arrangement. Hence, in recent years the adequacy of capacity and performance of the main span A-frames 

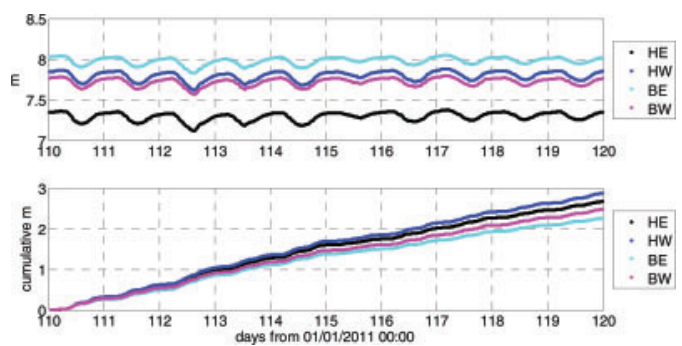

Figure 6. Diurnal variation of horizontal displacement at the bridge ends (top). Cumulative displacement of bridge decks over 10 days.

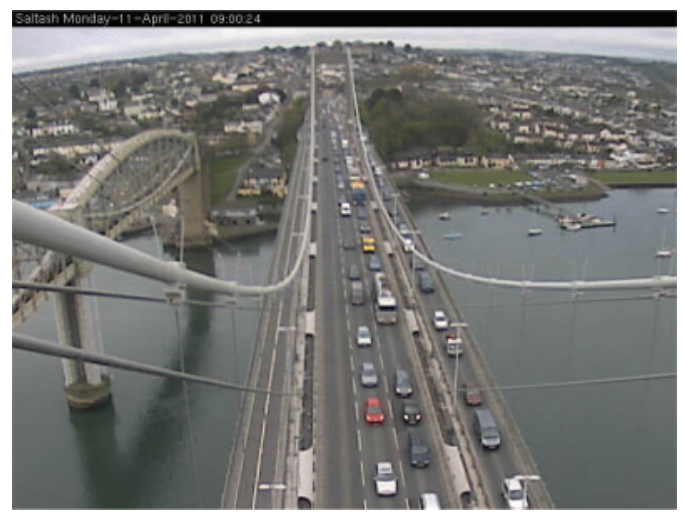

Figure 7.

has been questioned, based on the monitoring results which highlighted potential issue in the structure.

\section{BRIDGE DAY-TO-DAY TRAFFIC MANAGEMENT}

Modern bridge monitoring technology enables on-line access to continuous data streams, including video data, which can be used to see live performance of the bridge. Such systems may be used to control dayto-day bridge usage to avoid potential overstressing of structural elements.

Figure 15 shows a situation on a major partly loaded suspension bridge where one half of the bridge cross section is empty and the other is fully loaded due to a morning rush-hour accident.

As a consequence, the on-line monitoring system immediately registered that the stay cable tensions suddenly peaked whereas the natural frequency of the system dropped suddenly (Figure 16).

Figure 17 shows a major 6-lane road bridge in Continental Europe. The steel structural system with inclined supports acts as a 'shallow' frame with end columns rigidly connected to the structure that are 'sensitive' to temperature effects.

Figure 18 shows bending moment diagrams due to partial traffic load and temperature effects of $+35^{\circ} \mathrm{C}$. A potential problem for this bridge structure is that
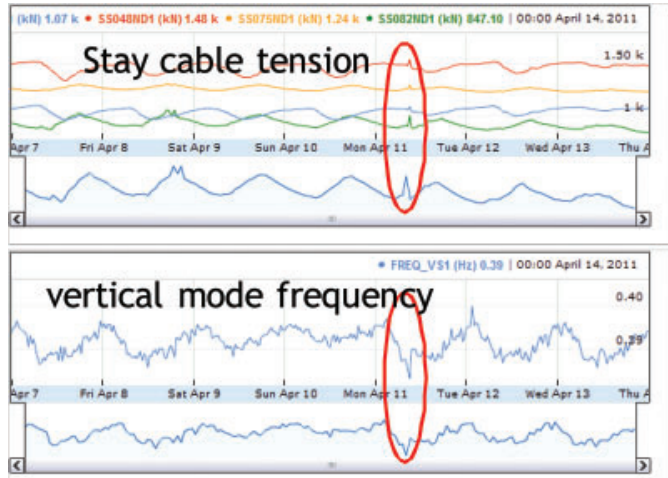

Figure 8. On line monitoring system picked up sudden tensions in stay cables and drop in the natural frequency of the bridge structure, which could be set up to trigger alert when managing traffic in cases of frequent bridge congestions.

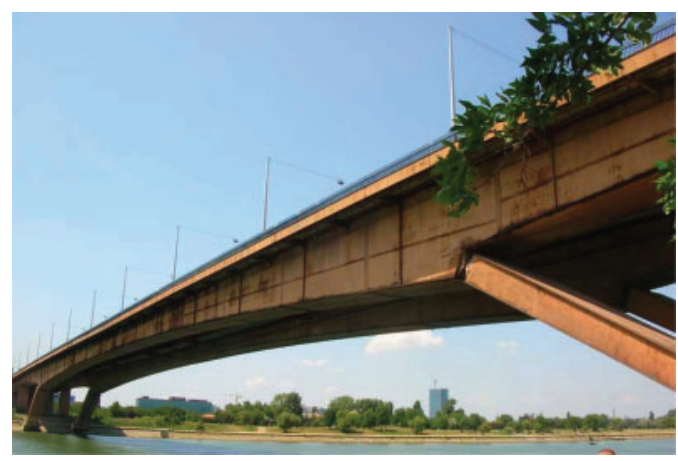

Figure 9. Major road steel bridge.

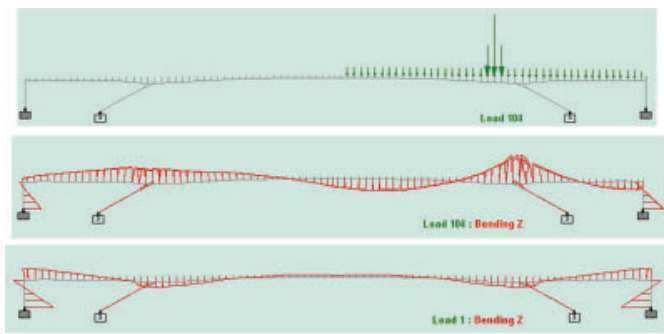

Figure 10. Critical load case - partial traffic loading combined with extreme temperature effects.

the combination of live load as shown in Figure 18 (top) with winter temperature of $-35^{\circ} \mathrm{C}$ will make sure that the two bending moments arithmetically add at the bottom of the vertical end column which is fixed.

This is potentially unsafe situation which can be managed by a permanent monitoring system which would monitor temperature and strain/stresses at the bottoms of the end columns. In case of low temperatures and if the strain readings require, the traffic over this vital bridge can be reduced, reducing the 
risk of a potentially unsafe situation that would otherwise require prevention by disruptive and expensive remedial work on the end columns.

\section{CONCLUSIONS}

This paper presents a vision for the future monitoring systems which will become normal requirements for management of bridges as key objects of national infrastructure in the UK and elsewhere. Rather than being pushed by authorities and legislation, we expect that bridge managers will recognize the clear business cases for investing in well-designed targeted monitoring.

To support this proposition, the paper presents three case studies where state-of-the-art bridge monitoring technology was used or potentially could be used to manage the following key aspects of bridge operation and maintenance:

- Deciding when to inspect and change bridge bearings, and

- Deciding when to close various traffic lanes to reduce probability of overstressing bridge structural components.

\section{REFERENCES}

[1] National Infrastructure Plan 2011, HM Treasury. http:/ /www . hm - treasury . gov . uk / national infrastructure_plan2011.htm

[2] http://www.infrastructurereportcard.org
[3] Moon FL, Aktan AE 2011, International guidelines for application of technology to bridges, for FHWA Long Term Bridge Program (draft), Also Aktan et al., 2000, ASCE EMD 126(7).

[4] http://www.fhwa.dot.gov/research/tfhrc/programs/ infrastructure/structures/ltbp

[5] Wynne, A. Worsening cracking problem closes M4 betwteen London and Heathrow, NCE, 7 July 2012. http://www.nce.co.uk/news/structures/worseningcracking-problem-closes-m4-between-london-andheathrow/8632760.article

[6] HM Treasury \& Infrastructure UK, 2010.

[7] Wenzel, H. The Character of SHM in Civil Engineering, Chapter 118, Encyclopedia of Structural Health Monitoring, John Wiley \& Sons Ltd., 2009.

[8] Moyo, P., Brownjohn, J. M. W. and Omenzetter, P. Highway bridge live loading assessment and load carrying capacity estimation using health monitoring system. Structural Engineering and Mechanics, 18(5), 609-626, 2011.

[9] Das, P. C. Assessment loading criteria for bridge decks, piers and parapets, Structures and Buildings, ICE, 146(1), 411-4212001. 